\title{
Post-seismic ionospheric response to the 11 April 2012 East Indian Ocean doublet earthquake
}

\author{
Anakuzhikkal Sudarsanan Sunil, Mala S Bagiya*', Chappidi Divakar Reddy, Manish Kumar and Durbha Sai Ramesh
}

\begin{abstract}
The 11 April 2012 East Indian Ocean earthquake is unique because of its largest ever recorded aftershock. The main earthquake occurred with a magnitude of $8.6 \mathrm{Mw}$ and was followed by a strong aftershock (8.2 Mw). Our analysis of the main shock indicates that the rupture was a mixture of strike-slip and thrust faults, and significant vertical surface displacements were observed during the event. The prime interest here is to study the post-seismic ionospheric disturbances, along with their characteristics. As both earthquakes had large magnitudes, they provided an opportunity to minimize the ambiguity in identifying the corresponding seismic-induced ionospheric disturbances. Approximately 10 min after both seismic events, the nearby ionosphere started to manifest electron density perturbations that were investigated using GPS-TEC measurements. The epicenters of both events were located south of the magnetic equator, and it is believed that the varying magnetic field inclination might be responsible for the observed north-south asymmetry in the post-seismic total electron content (TEC) disturbances. These disturbances are observed to propagate up to approximately 1,500 km towards the north side of the epicenter and up to only a few hundred kilometers on the south side. The frequency analysis of the post-seismic TEC disturbances after both earthquakes exhibits the dominant presence of acoustic frequencies varying between approximately 4.0 to $6.0 \mathrm{mHz}$. The estimated propagation velocities of the post-seismic TEC disturbances during the main shock $(0.89 \mathrm{~km} / \mathrm{s})$ and aftershock $(0.77 \mathrm{~km} / \mathrm{s})$ confirm the presence of an acoustic frequency as the generative mode for the observed TEC fluctuations.
\end{abstract}

Keywords: Strike-slip faults; Post-seismic ionospheric disturbances; Acoustic waves during seismic events; Earthquake and GPS-TEC

\section{Background}

The origin of perturbations in ionospheric electron density can be traced to various sources. They can originate due to forces either from above (e.g., solar, geomagnetic) or below (e.g., lower atmospheric, seismic) the ionosphere. In particular, seismic activity is one of the potential sources that can affect the ionospheric electron density at smaller scales prior to, during, or after an earthquake occurrence (e.g., Liu et al. 2010; Rolland et al. 2011a, Rolland et al. 2011b; Astafyeva et al. 2013). These electron density variations are, respectively, known as pre-, co-, and post-seismic ionospheric disturbances. It is well known that during the occurrence of an earthquake, the surface experiences horizontal as well as vertical displacements, depending

\footnotetext{
* Correspondence: bagiyamala@gmail.com

Indian Institute of Geomagnetism, Plot 5, Sector 18, Near Kalamboli Highway, New Panvel (W), Navi Mumbai 410218, India
}

upon the type of rupture fault. Normal and reverse thrust faults lead to significant vertical surface displacements during the earthquake, while strike-slip faults alone generally produce only horizontal displacements. Shallow thrust earthquakes, giving strong vertical ground displacements, produce infrasonic pressure waves in the vicinity of the neutral atmosphere. These neutral atmospheric disturbances, known as acoustic gravity waves, propagate upwards to ionospheric altitudes and create disturbances in the electron density there (e.g., Calais and Minster 1998). These disturbances are well known as seismo-traveling ionospheric disturbances (STID) (e.g., Liu et al. 2011) or co-seismic ionospheric disturbances (CID) (e.g., Heki and Ping 2005). In addition to ground vertical motion, horizontally propagating Rayleigh surface waves (Oliver 1962) also introduce acoustic waves into the nearby neutral atmosphere, which later arrive at the ionospheric 
altitudes and generate electron density variations there. The Rayleigh wave propagates horizontally with typical velocities of approximately 3 to $5 \mathrm{~km} / \mathrm{s}$ on the surface of the Earth. While propagating away from the epicenter, it generates acoustic wave perturbations that reach ionospheric altitudes and create electron density variations. Although the first effects to be seen in the ionosphere would be due to vertical surface displacements during the shock, the far-field ionospheric perturbations due to the Rayleigh wave would appear earlier because of its higher velocity. It is conjectured that tsunami waves in the ocean generate gravity waves that propagate obliquely upwards and interact with the ionospheric electron density.

Acoustic gravity waves are mainly generated immediately after the main shock (e.g., Astafyeva et al. 2009; Matsumura et al. 2011; Saito et al. 2011; Rolland et al. 2011a) and reach ionospheric altitudes after 10 to 15 min of the main shock. It is believed that upward propagation of wave perturbations happens in the vicinity of the earthquake epicenter or within the so-called earthquake preparation zone. Using a case study, Otsuka et al. (2006) suggested that there can be multiple sources for acoustic wave generation along the rupture that propagate away from the epicenter at the rupture velocity. Heki and Ping (2005) have empirically shown that only acoustic waves emanating within the zenith angles of $0^{\circ}$ to $20^{\circ}$ can reach ionospheric heights and affect the electron density. The remaining waves get reflected, mainly because of atmospheric temperature variations, and return to the ground. Acoustic waves at ionospheric heights would introduce electron density perturbations that propagate further along geomagnetic field lines. Heki and Ping (2005) have empirically shown that propagation along the field lines is highly dependent on the magnetic inclination of that region. According to them, if the angle between the acoustic-wave-induced post-seismic ionospheric perturbations and the local geomagnetic field is either 0 or 180, then propagation will be hampered. In other cases, perturbations can propagate farther depending on the angle with respect to the geomagnetic field lines.

Induced ionospheric electron density perturbations related to seismic activity are often observed with various radio techniques, such as HF Doppler sounding, ionosonde, and global positioning system (GPS) (e.g., Tanaka et al. 1984; Yao et al. 2012; Rolland et al. 2011a; Rolland et al. 2011b). In recent times, the GPS network has been widely used to study co- and post-seismic ionospheric disturbances (e.g., Liu et al. 2010; Rolland et al. 2011a; Rolland et al. 2011b; Astafyeva et al. 2013 and references therein). Individual investigations (e.g., Liu et al. 2010; Rolland et al. 2011a; Rolland et al. 2011b; Tsugawa et al. 2011; Kakinami et al. 2012) have been able to characterize the different types of seismicinduced ionospheric disturbances, such as those produced by acoustic waves caused by propagating Rayleigh surface waves, by acoustic waves and atmospheric gravity waves from the ionospheric epicenter, and by co-seismic surface motions, the post-seismic 4-min monoperiodic atmospheric resonances, tsunamis, and co-seismic depletion in GPS-derived total electron content (TEC) followed by enhancements over the tsunami origin region.

In the present case, we investigate various characteristics of post-seismic ionospheric disturbances (propagation extent, generative wave frequency, propagation velocity, and direction) associated with the Indian Ocean doublet earthquake that occurred on 11 April 2012. From the point of view of seismicity, this particular earthquake is unique in many ways (Pollitz et al. 2012; Yue et al. 2012). This was the largest strike-slip earthquake ever recorded. The main earthquake $(8.6 \mathrm{Mw})$ was followed by a powerful aftershock of $8.2 \mathrm{Mw}$, the highest ever recorded aftershock. Although many results have been reported (e.g., Perevalova et al. 2014 and references therein) pertaining to the post-seismic ionospheric variations, this particular case study is new from the point of view of the complex earthquake fault mechanisms. This aspect, in terms of the vertical surface displacements, is discussed in detail. This is significant because, as strike-slip earthquakes are less frequent in nature, post-seismic ionospheric disturbances that pertain to strike-slip earthquakes have rarely been reported (e.g., Astafyeva et al. 2014). Another major reason for selecting this event is to minimize the ambiguities in identifying the relatively feeble (small-scale) earthquakeinduced post-ionospheric disturbances. It is often difficult to unambiguously associate the observed ionospheric disturbances during a seismic event exclusively to the event, since competing candidate phenomena can also operate in the same time window. This ambiguity is addressed in this study, and it is also demonstrated that the observed ionospheric disturbances are indeed induced by the earthquakes. The selected time window of events illustrates two major earthquakes that occurred with a time gap of approximately $2 \mathrm{~h}$ and $5 \mathrm{~min}$. Both quakes occurred before sunset on a geomagnetically quiet day $(\mathrm{Ap}=4)$. These may preclude many other potential sources of ionospheric disturbance. The following sections describe the observations and discussions pertaining to the ionospheric response to this twin seismic event.

\section{Methods}

Figure 1a shows the earthquake epicenters during both earthquakes. The first earthquake with $\mathrm{Mw}=8.6$ (08:38:37 UTC) in the Indian Ocean, about $100 \mathrm{~km}$ west 


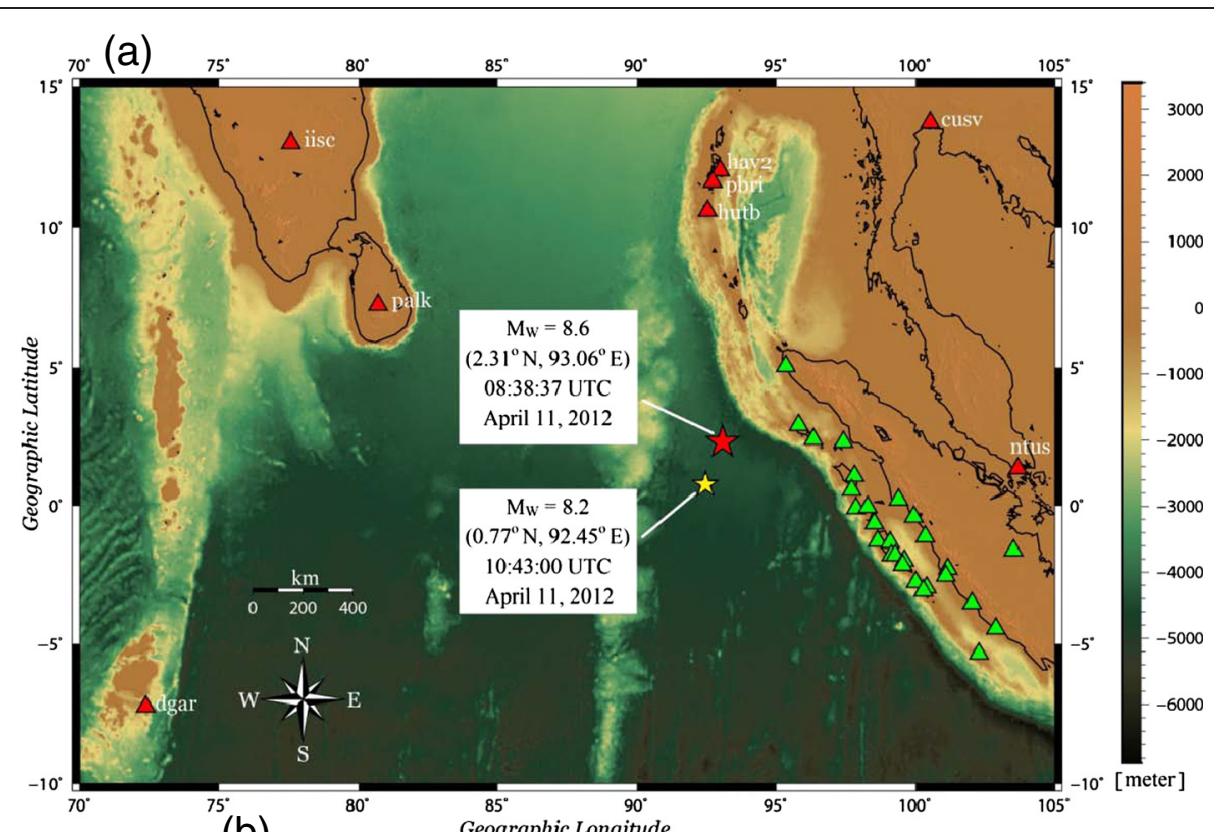

(b)

$S^{1}$

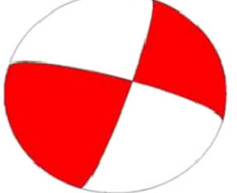

$S^{3}$

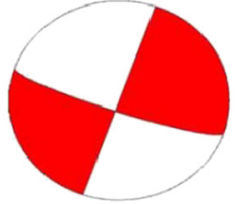

$\mathrm{S}^{2}$

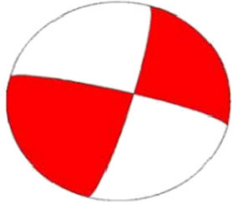

$\mathrm{S}^{4}$

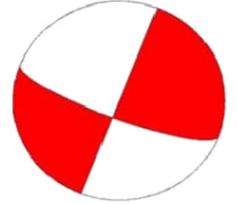

\begin{tabular}{|l|l|l|l|l|}
\hline & $\mathrm{S}^{1}$ & $\mathrm{~S}^{2}$ & $\mathrm{~S}^{3}$ & $\mathrm{~S}^{4}$ \\
\hline Strike & 286 & 16 & 109 & 111 \\
\hline Dip & 75 & 80 & 80 & 74 \\
\hline Rake & 170 & 10 & 180 & 180 \\
\hline Slip (m) & 37 & 11 & 26 & 12 \\
\hline
\end{tabular}

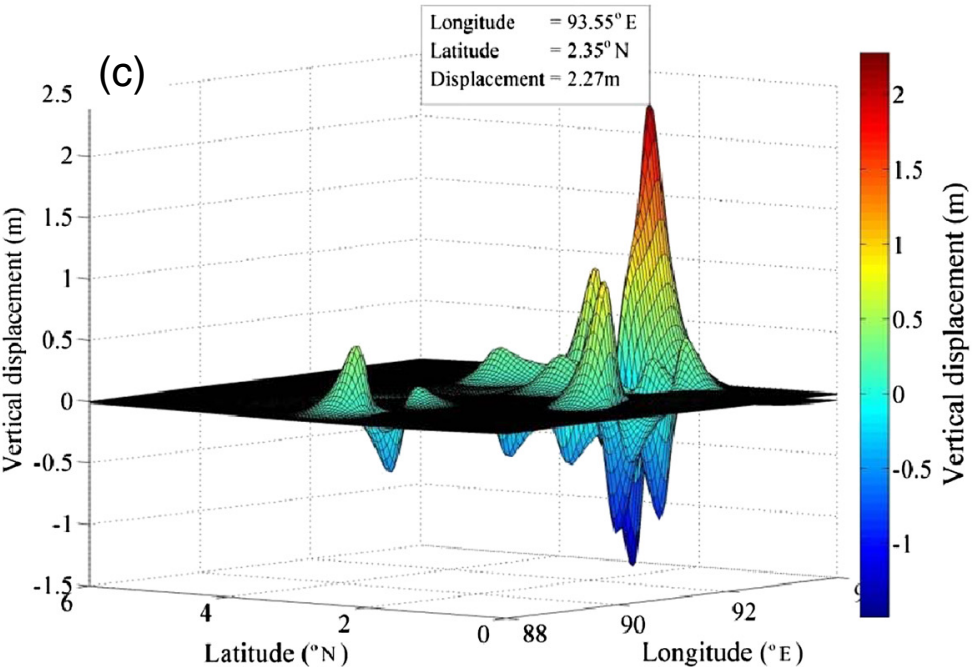

Figure 1 (See legend on next page.) 
(See figure on previous page.)

Figure 1 Locations of the earthquake epicenters, beach ball diagrams showing the four-fault mechanisms, and vertical surface displacement. (a) Locations of epicenters during the main shock (red star) and aftershock (yellow star). Locations of GPS receiver stations used in the present study are also shown in the plot. Red triangles show the IGS GPS receiver stations, while green triangles represent the SuGAr GPS receiver stations. (b) Four-fault mechanisms during the main shock that lasted approximately $160 \mathrm{~s}$. The parameters used to plot the fault mechanisms are from Yue et al. (2012) and are shown here in the table below the plot. It is clear that the main shock occurred with a mixture of strike-slip and thrust faulting. (c) Vertical surface displacement associated with the main shock. It can be seen that because of the small thrust component, a significant vertical displacement of approximately $2.27 \mathrm{~m}$ was observed near the epicenter during the main shock.

of the Sumatra subduction zone, was the largest intraplate strike-slip earthquake in history. The epicenter of this event was located at $2.31^{\circ} \mathrm{N}, 93.06^{\circ} \mathrm{E}$ (shown by the red star in the figure). After approximately 2 hours (10:43:00 UTC), it triggered another great strike-slip earthquake of $\mathrm{Mw}=8.2$ in its vicinity, with an epicenter at $0.77^{\circ} \mathrm{N}, 92.45^{\circ} \mathrm{E}$ (shown by the yellow star in the figure). Figure $1 \mathrm{~b}$ represents the beach ball diagram showing the four-fault mechanisms during the main shock. It can be seen that the main earthquake source has strike-slip and thrust mechanisms.

From the tectonics point of view, this twin earthquake event had a very complex four-fault rupture during the main shock, and the large aftershock occurred with a bilateral rupture fault (Pollitz et al. 2012; Yue et al. 2012). The possible four-fault mechanisms simulated with the strike, dip, and rake values taken from Yue et al. (2012) are represented in Figure $1 \mathrm{~b}$ for the main shock. It can be seen that it was not a pure strike-slip earthquake. The main rupture lasted for approximately $160 \mathrm{~s}$ (Yue et al. 2012), exhibiting a mixture of strike-slip and thrust faulting (e.g., Meng et al. 2012). It is known that during a pure strike-slip earthquake, the surface may not experience any significant vertical displacements. Thus, the vertical mechanical oscillations in the earth-bounded atmosphere, and later its manifestations to ionospheric heights, may not be significant during any pure strikeslip event. In order to justify the mixed-fault mechanism during the main shock (Figure 1b), vertical surface displacements were simulated with the help of Okada (1985) and the parameters given by Yue et al. (2012). Figure 1c shows the vertical displacement simulated over the time period of approximately $110 \mathrm{~s}$ for four different focal parameters. It is noted that the surface surrounding the epicenter had oscillated up and down significantly during the main shock, with a maximum vertical displacement of approximately $2.27 \mathrm{~m}$. As mentioned earlier, the vertical surface displacements produce infrasonic pressure waves in the nearby atmosphere, which propagate upward with increasing amplitude as the atmospheric density decreases with height. There is convincing evidence that the neutral atmospheric perturbations manifest as ionospheric electron density perturbations at different heights, from $100 \mathrm{~km}$ to as high as $300 \mathrm{~km}$ (e.g., Rolland et al. 2011a).
To identify the post-seismic ionospheric disturbances associated with this twin seismic event, if any, GPS-TEC data from the Sumatran GPS Array (SuGAr) and International GNSS Service (IGS) networks were extracted (source: http://sopac.ucsd.edu). GPS stations used in the present investigations are shown as triangles in Figure 1a. Green triangles represent the SuGAr stations, while red triangles represent the IGS stations. The datasampling rate for SuGAr receivers is $15 \mathrm{~s}$, and that of the IGS receivers is $30 \mathrm{~s}$.

TEC represents the total number of free electrons along the line of sight from satellite to receiver. It is mainly weighted by the ionospheric F-region (the region where maximum ionization occurs); thus, it provides an opportunity to detect any acoustic, gravity, or both types of wave perturbations in the upper atmosphere. TEC, both from SuGAr and IGS receivers, are calculated here using differential carrier phase measurements and code measurements available in the receiver-independent exchange (RINEX) file format. The dual frequency carrier phase measurements provide the smooth slant TEC with an integer ambiguity. Slant TEC calculated from the code measurements are absolute but noisy. We calculated the absolute slant TEC using code measurements, and smoothed it with the carrier phase measurements. The estimated slant TEC is converted to vertical TEC (VTEC) using a mapping function (Mannucci et al. 1993) as follows:

$$
\begin{aligned}
& \mathrm{VTEC}=M \times \mathrm{STEC} \\
& M=\left[1-\left(\frac{\cos (E)}{1+\frac{h}{R_{\mathrm{E}}}}\right)^{2}\right]^{\frac{1}{2}}
\end{aligned}
$$

where $E$ is the satellite elevation angle, $h$ is the ionospheric shell height (300 $\mathrm{km}$ is used here), and $R_{\mathrm{E}}$ is the Earth's mean radius. The VTEC is corrected for the monthly satellite differential code biases (source: ftp:// ftp.unibe.ch/aiub/CODE/). For further study, the absolute VTEC is subtracted from its previous value every $30 \mathrm{~s}$. This is a simple two-point differentiation (Liu et al. 2006), and the resultant VTEC is called the differential TEC. To minimize the multipath effect, an elevation mask of $20^{\circ}$ is applied. 


\section{Results and discussion}

\section{Propagation characteristics of post-seismic ionospheric} disturbances

While examining the differential TEC variations during and after the earthquakes, it was noticed that approximately 10 to $12 \mathrm{~min}$ after the occurrence of both earthquakes, sudden irregular TEC fluctuations were observed by more than one satellite at various GPS sites on 11 April 2012. Henceforth, the satellites will be identified by their pseudo random number (PRN). After the first earthquake, PRN 32 and PRN 16 showed TEC fluctuations, while PRN 32 and PRN 20 detected similar types of TEC variations after the second earthquake.

To confirm that the observed TEC fluctuations on April 11 were due to the twin seismic activity, the differential TEC variations at one of the SuGAr stations, umlh, as observed by PRN 32, were examined. The differential TEC variations observed at umlh for five consecutive days starting from April 9 through April 13, 2012 are presented in Figure 2. It can be seen that sudden TEC variations are clearly identifiable approximately $10 \mathrm{~min}$ after the origin time of both the earthquakes on April 11. No such variations were observed on the remaining 4 days.

Figure 3a depicts the locations of various SuGAr and IGS stations (triangles) along with the ionospheric piercing point (IPP) positions of PRN 32 (blue circles) and PRN 16 (red circles) calculated at an ionospheric height of $300 \mathrm{~km}$ approximately $10 \mathrm{~min}$ after the first earthquake on April 11. The respective IPPs are labeled according to the receiving station codes. As mentioned earlier, the postseismic TEC variations after the second earthquake were observed by PRN 32 (blue circles) and PRN 20 (red circles). The observational IPP positions for these PRNs are shown in Figure 3b. Both earthquakes locations are labeled and represented by star symbols in the figures.

Figure 4a,b shows the differential TEC variations from 08:00 to 10:00 UTC as observed by PRN 32 and PRN 16 at various stations depicted in Figure 3a. By assuming that the Earths' surface remains flat a few degrees around the equator, the horizontal slant distance between the epicenter and each IPP is calculated and shown in Figure 4a,b. Although the distance from the highest initial uplifted height is more suitable while calculating the distances from the epicenter (e.g., Kakinami et al. 2012, 2013), these values may not change significantly in our case, since the epicenter $\left(2.31^{\circ} \mathrm{N}, 93.06^{\circ} \mathrm{E}\right)$ and the place of highest initial height $\left(2.35^{\circ} \mathrm{N}, 93.55^{\circ} \mathrm{E}\right)$ are nearby. Clear signatures of post-seismic TEC disturbances were clearly observed by both PRNs approximately $10 \mathrm{~min}$ after the first earthquake occurrence. It is also notable that the largest magnitude of the seismically

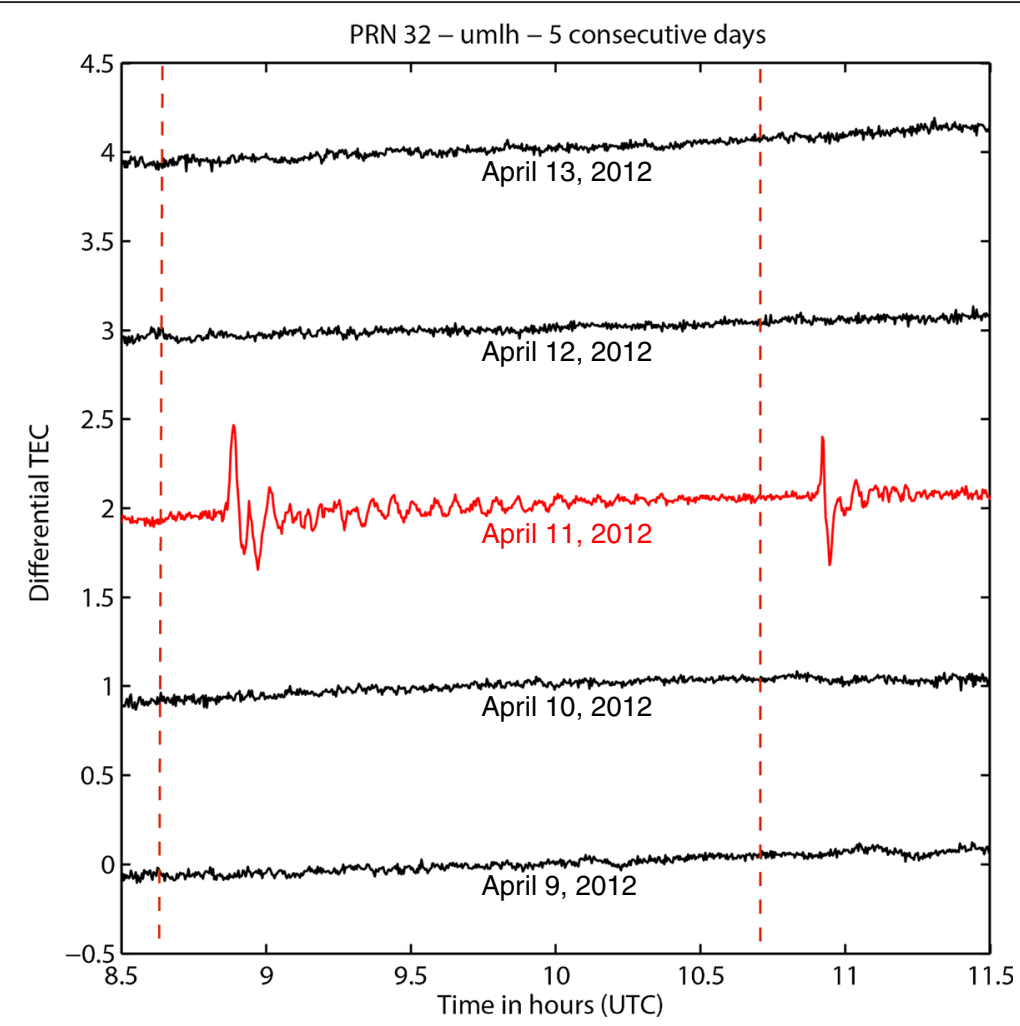

Figure 2 Differential TEC variations on 9 to 13 April 2012 from one SuGAr station, umlh. Two red bars show the times of both earthquakes. It can be seen that after both events, the TEC started to show irregular fluctuations. These fluctuations were absent on other days. 

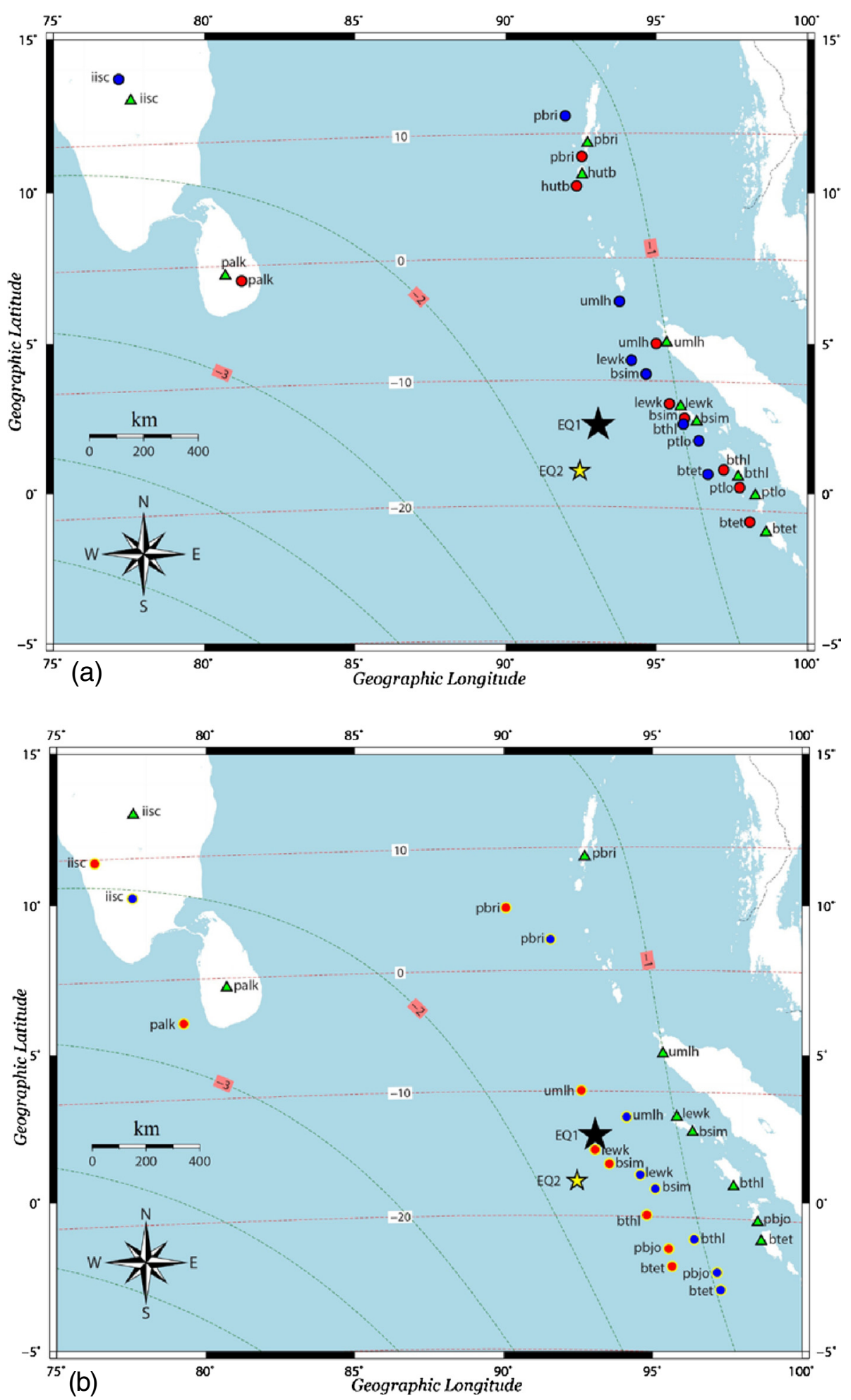

Figure 3 Plots showing locations of various SuGAr and IGS stations and positions for PRN 32 and PRN 20. (a) Plot showing IPP positions for PRN 32 (blue circles) and PRN 16 (red circles) approximately 10 min after the main shock. (b) IPP positions for PRN 32 (blue circles) and PRN 20 (red circles) approximately 10 min after the aftershock. Green curved lines represent magnetic declination, while red curved lines represent magnetic inclination. 

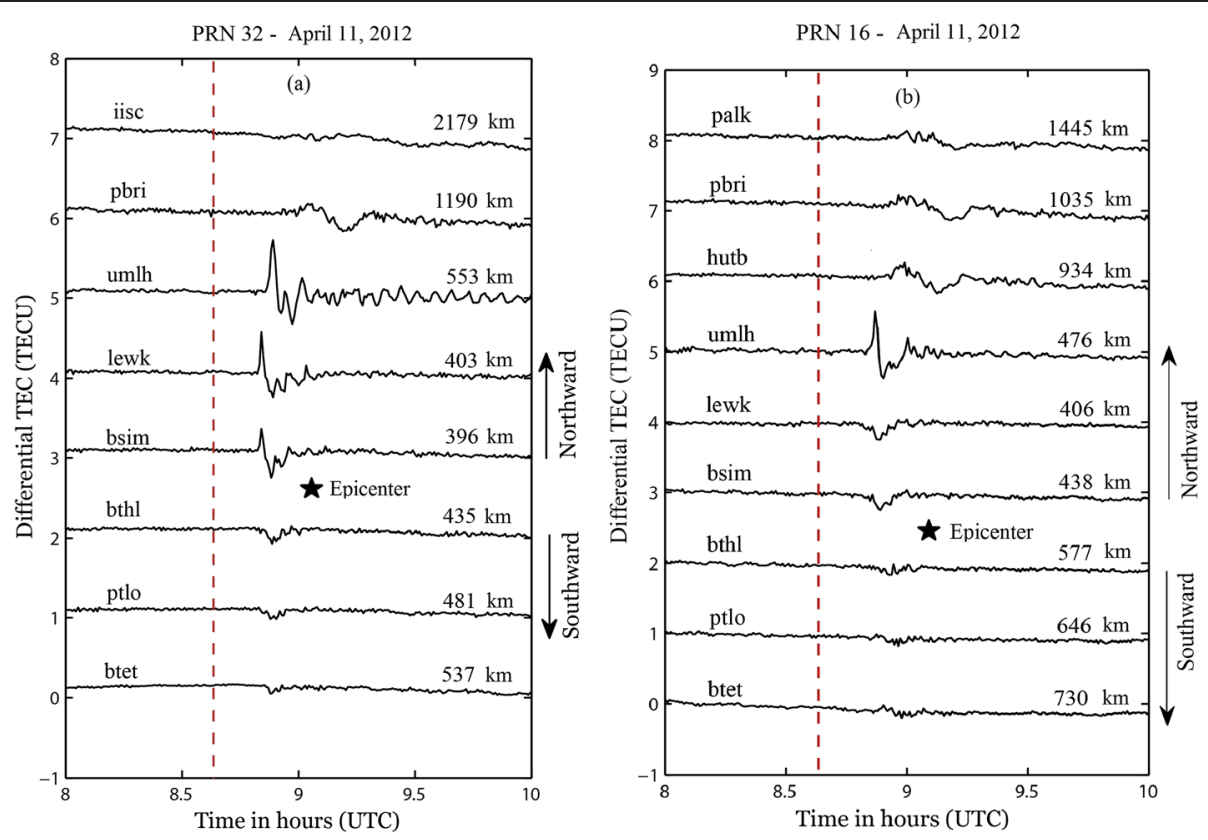

Figure 4 Differential TEC variations from 08:00 to 10:00 UTC as observed by PRN 32 and PRN 16. (a) Differential TEC variations from PRN 32 from SuGAr and IGS stations as observed between 08:00 and 10:00 UTC on 11 April 2012. (b) Same as (a) but from PRN 16. The north and south directions from the epicenter are shown in the figure. The distance of the respective station from the epicenter is also depicted. It is interesting to note that the TEC fluctuations propagated as far as pbri (location can be seen in Figure 3a) in the north but propagated only a few hundred kilometers in the south. Similar behavior was exhibited by PRN 16 TEC fluctuations. (Epicenter location shown by star is approximate, and not to scale).

induced TEC disturbances occurred north of the epicenter at umlh (approximately $553 \mathrm{~km}$ from the epicenter) after the first earthquake, as observed by PRN 32, and at approximately $476 \mathrm{~km}$ as observed by PRN 16. It is interesting to note that the post-seismic TEC disturbances were observed as far as sites pbri, palk, and iisc (approximately 1,500 km from the epicenter), north of the epicenter, albeit with decreasing magnitudes. The stations located south of the epicenter yield relatively smaller TEC disturbances that propagated only up to a few hundred kilometers. The largest amplitude of postseismic TEC disturbances occurred within approximately $730 \mathrm{~km}$ south of the epicenter.

Figure 5a,b shows the post-seismic TEC variations as observed by PRN 32 and PRN 20 after the second earthquake. During the second earthquake, clear TEC disturbances were also observed with increasing magnitude north of the epicenter. On the southern side, the disturbances were observed but with very small magnitude. The amplitudes of seismically induced TEC disturbances depend on the magnitude of the earthquake (e.g., Astafyeva et al. 2013) and geomagnetic field direction (e.g., Otsuka et al. 2006; Astafyeva and Heki 2009; Choosakul et al. 2009; Kakinami et al. 2013), in addition to the background ionospheric density. It is notable that the magnitude and duration of the TEC disturbances during both events depend mainly on the earthquake magnitude. In order to verify the role of background ionospheric density in deciding the magnitude of TEC disturbances, the absolute VTEC variations with time as observed by PRN 32 at various stations are shown in Figure 6. It is clear that the VTEC increases with time, except at pbri and iisc. This behavior may be attributed to latitudinal variation of electron density, well known as the Equatorial Ionization Anomaly (EIA). Irrespective of the increase in VTEC with time, the observed TEC disturbances during the second earthquake show smaller amplitudes compared to the first. Thus, it seems that the background ionospheric density does not contribute much to the observed magnitude change of the post-seismic TEC disturbances. Therefore, the main driver behind the amplitude variations of the TEC disturbances during both events is the magnitude of the respective earthquake.

The reasons for the hemispheric asymmetry observed in the magnitude of TEC perturbations can be understood on the basis of the empirical relation given by Heki and Ping (2005). It is known that the motion of charged particles is mainly controlled by the geomagnetic field at the ionosphere F-region altitudes. As the charged particles enter a magnetic field, they gyrate around it and move further. The propagation of charged particles in this way is highly dependent on the angle between their velocity vector and the local magnetic field. 

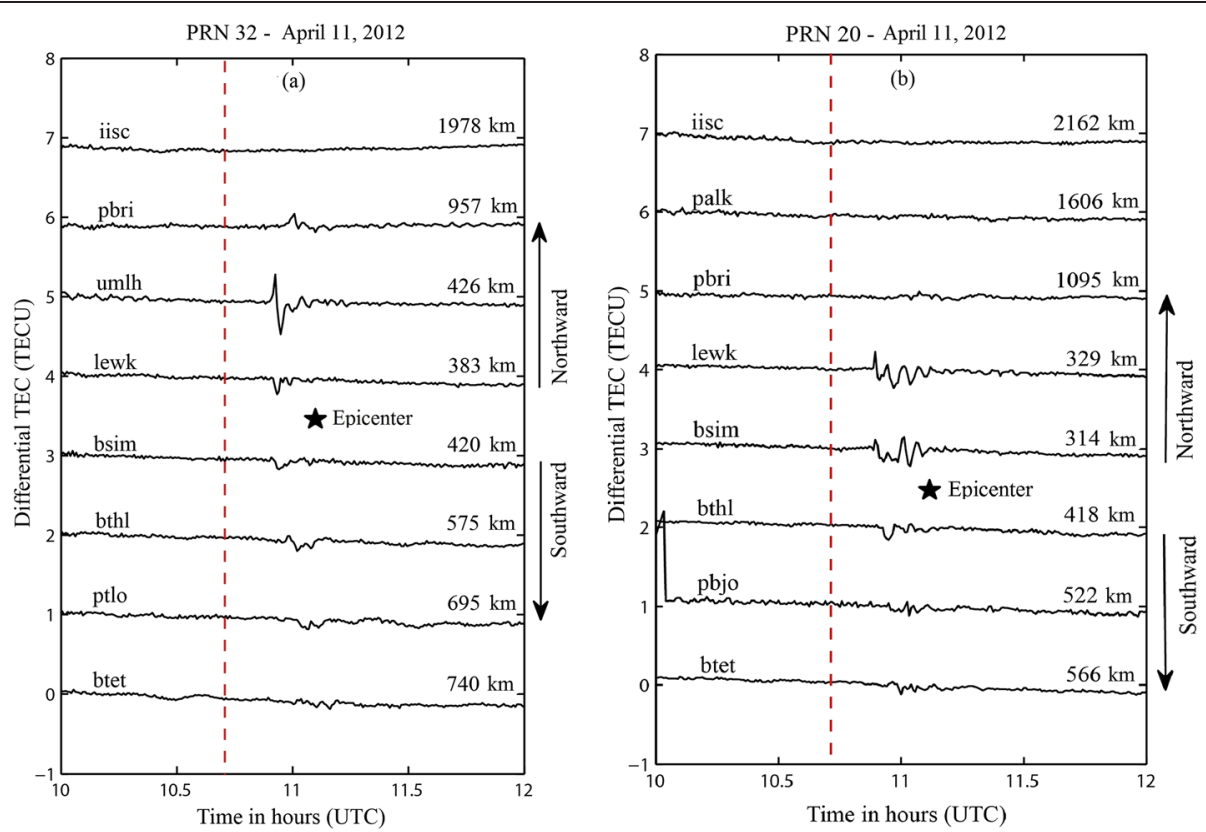

Figure 5 Same as Figure 4, but for PRN 32 (a) and PRN 20 (b) at 10:00 to 12:00 UTC. It can be seen that the TEC fluctuations were feeble after the aftershock compared to what was observed after the main shock. (Epicenter location shown by star is approximate, and not to scale).

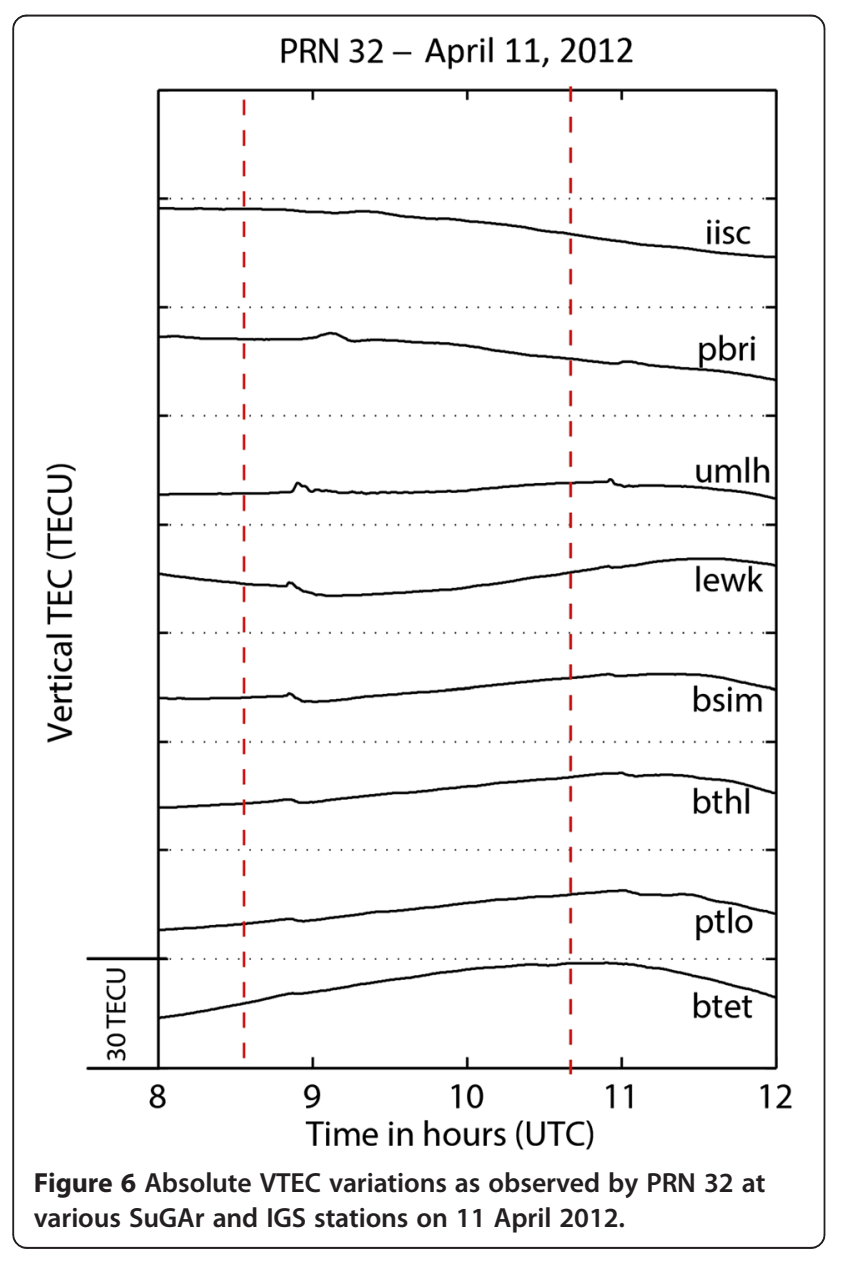

During a seismic event, once excited by an acoustic wave or acoustic gravity waves, further propagation of post-seismic ionospheric electron density disturbances depends on their orientation with respect to the ambient magnetic field direction. If the propagating wave fronts are parallel to the ambient geomagnetic field, then the Lorentz force under whose influence the perturbations can travel further would be zero. In such a scenario, the density disturbances may not propagate ahead and cease within a short duration.

The geomagnetic dip angle at the epicenter of the first earthquake is $-13.59^{\circ}$, and the declination is $-1.5^{\circ}$. The geomagnetic inclination and declination of the second earthquake epicenter is $-17.26^{\circ}$ and $-1.74^{\circ}$, respectively. The magnetic field components (dip and declination) for this region are calculated using the International Geomagnetic Reference Field (IGRF) 11 and shown in Figure 3a,b with dotted lines. IGRF 11 is a standard mathematical description of the Earth's main magnetic field. The latest version (IGRF 11) released by the International Association of Geomagnetism and Aeronomy (IAGA) is used here to derive the field inclination and declination. It can be seen that the epicenter of the first earthquake is in the magnetic southern hemisphere. The southward-propagating TEC perturbations would become parallel to the more inclined geomagnetic field in the southern hemisphere within a short time duration. Thus, the TEC perturbations propagating in the southern hemisphere occur within a very short distance from the epicenter. It seems that the TEC perturbations had 
almost merged with the background after this. In contrast, the northward-propagating TEC perturbations could travel comparatively longer distances because the inclination gradually decreases towards the magnetic equator side of the epicenter. The magnetic equator-ward propagation of TEC perturbations after both earthquakes reached as far as site pbri to the north.

\section{Evidence of the role of acoustic resonant frequencies in producing post-seismic ionospheric disturbances} Using the free oscillation modes of the Earth with the atmosphere, Lognonné et al. (1998) predicted two infrasonic frequencies that fall in the range of 3.7 to $3.8 \mathrm{mHz}$ and 4.35 to $4.48 \mathrm{mHz}$, at which strong coupling between the Earth and its atmosphere occurs. These frequencies are termed fundamental acoustic resonance frequencies. Rolland et al. (2011a) confirmed the existence of these frequencies during their study of the great Tohoku earthquake and showed that these frequencies remained trapped for approximately $2 \mathrm{~h}$ after the main shock. In addition, they also recorded the signatures of the gravity acoustic mode (ranging between 0.5 and $2.9 \mathrm{mHz}$ ) for approximately $1 \mathrm{~h}$ at ionospheric heights in terms of TEC perturbations. However, Saito et al. (2011) reported, using TEC observations, an acoustic resonance lasting for $4 \mathrm{~h}$ in the vicinity of the epicenter during the Tohoku earthquake.

In order to identify the frequency range that might have caused the observed post-seismic ionospheric disturbances, the absolute slant TEC observations from PRN 32 are detrended by subtracting the seven-point (105 s) moving average from slant TEC every $15 \mathrm{~s}$. This procedure eliminates frequencies higher than $9.5 \mathrm{mHz}$. The resultant, detrended TEC (dTEC) is then subjected to wavelet analysis in order to determine the dominant frequency range. The dTEC variations and frequency spectrum for the same are presented in Figure 7a, with the power in terms of TECU ${ }^{2}$. It is evident from the bottom panel of Figure $7 \mathrm{a}$ that the predominant frequency is centered at approximately $4.79 \mathrm{mHz}$ after the occurrence of the first earthquake. During the second earthquake, the dominant frequencies vary between approximately 4.0 and $6.0 \mathrm{mHz}$. The derived frequency plots provide evidence of the role of acoustic wave perturbations in generating the observed post-seismic TEC disturbances. It is interesting to note that the trapped mode frequency of approximately 4.0 $\mathrm{mHz}$ can also be observed for a duration of approximately $1 \mathrm{~h}$ after the first earthquake. This behavior is depicted in Figure $7 \mathrm{~b}$ with a higher time resolution. The top panel shows the dTEC between 09:15 UTC and 10:30 UTC, and its frequency spectrum is shown in the bottom panel. An interesting point of this particular study is the effect of the interaction between these two earthquakes on the ionosphere. It can be seen from Figure $7 \mathrm{a}$ that the detrended TECs have almost approached the quiet hour values well before the occurrence of the second earthquake. A similar phenomenon is also apparent in the wavelet spectra in Figure $7 \mathrm{~b}$. This clarifies that there was no interaction between the earthquake-induced wave disturbances at this ionospheric height.

The presence of acoustic frequencies can be confirmed from the travel time diagrams in Figure 8. Differential TECs, derived from PRN 32 observations, for different sites south of the epicenters are plotted as a function of
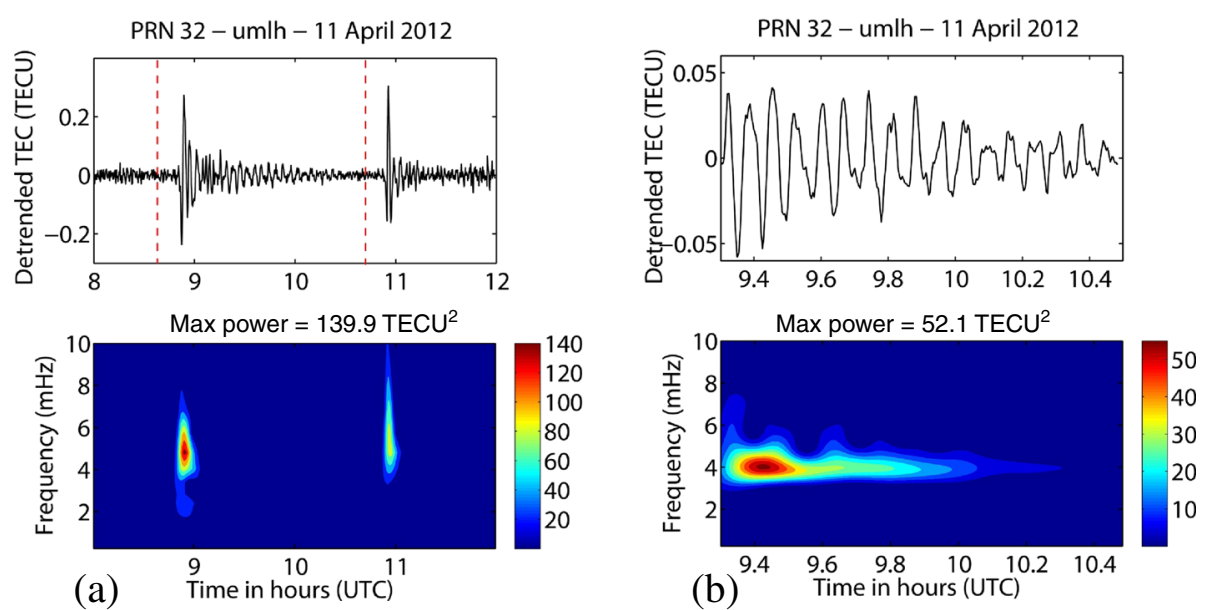

Figure 7 Detrended TEC, wavelet frequency spectrum, and trapped fluctuations. (a) Detrended TEC from PRN 32 observations at site umlh at 08:00-12:00 UTC (top panel). Wavelet frequency spectrum for the same is shown in bottom panel. The dominant presence of an acoustic frequency $(4.49 \mathrm{mHz})$ during the main shock clearly indicates that the observed TEC fluctuations were produced by acoustic wave frequencies, similar to the aftershock-induced fluctuations. Here, however, the dominant frequencies vary from approximately 4.0 to $6.0 \mathrm{mHz}$. (b) The acoustic trapped mode after the main shock was also observed for approximately $50 \mathrm{~min}$. The top panel shows trapped fluctuations with high-time resolution, and the bottom panel shows the wavelet frequency spectrum. 

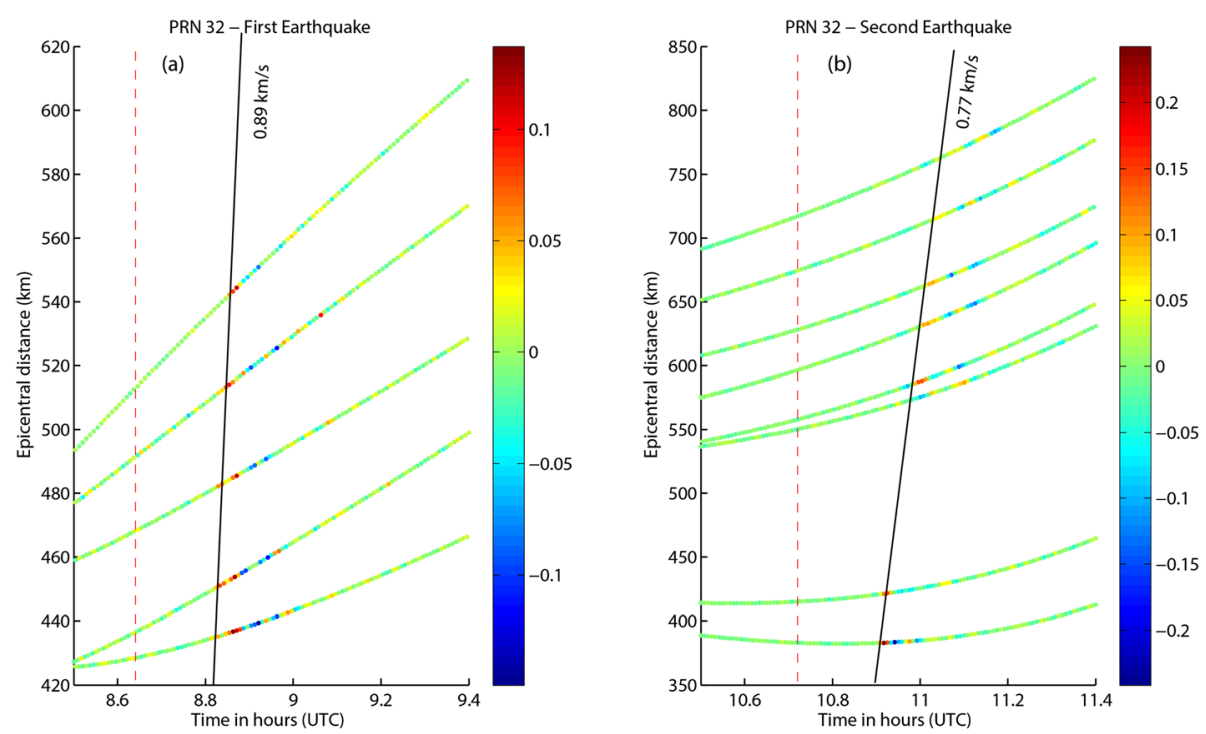

Figure 8 Travel time diagrams for ionospheric TEC perturbations as a function of time and epicentral distance. Propagation velocities after the main shock and the aftershock are shown for PRN 32 in (a) and (b), respectively.

time (in UTC) and epicentral distance (line of sight distance between IPP at $300-\mathrm{km}$ altitude and epicenter). The velocity is estimated as the slope of the line shown in the figure. The line shows the arrival of the postseismic disturbances at respective sites. It can be seen that the velocity values are 0.89 and $0.77 \mathrm{~km} / \mathrm{s}$ for the first and second earthquakes, respectively. The derived velocities indicate that acoustic waves are indeed the main driver of the observed post-seismic TEC disturbances during both events. North of the epicenter, there were fewer observing stations during the second earthquake. Thus, in order to reduce the ambiguity, only the southern stations are considered for the velocity calculation.

The obtained acoustic velocities during both earthquakes rule out the possibility of a Rayleigh wave as one of the generative mechanisms for the observed postseismic TEC disturbances using the present dataset. Thus, it can be stated that multiple acoustic wave sources propagating along the rupture after the twin seismic event might have induced acoustic waves in the nearby atmosphere, which results in excited ionospheric electron density perturbations on arrival at ionospheric altitudes.

The GPS satellite IPP velocity is approximately $1 \mathrm{~km} / \mathrm{s}$ at the height of approximately $300 \mathrm{~km}$. This height is the IPP height where the TEC calculation is performed. This means that, at a height of approximately $300 \mathrm{~km}$, the satellite IPP velocity value is very close to the estimated post-seismic TEC disturbance velocities. In view of this, there would not be any significant relativistic Doppler shift in the power spectrum of Figure $7 \mathrm{a}$ due to satellite motion. However, the change in generative frequency from approximately $4.79 \mathrm{mHz}$ during the first event to approximately $5 \mathrm{mHz}$ during the second event may be due to the change in the ionospheric F-region wind velocity. The F-region wind velocity varies with local time, so in the absence of direct wind measurements and accurate model values, this frequency shift can only be stated in terms of F-region changing wind velocity.

\section{Conclusions}

Using GPS TEC measurements, we analyzed the ionospheric signatures of the 2012 Indian Ocean doublet earthquake. Two major earthquakes with magnitudes $\mathrm{Mw}=8.6$ and $\mathrm{Mw}=8.2$ occurred on 11 April 2012, and the ionosphere responded by producing TEC disturbances over the Indian Ocean and at stations located as far as India approximately $10 \mathrm{~min}$ after the main shocks. The epicenters of both earthquakes are located south of the geomagnetic equator. The fault mechanism and associated vertical surface displacements derived using the available parameters (Yue et al. 2012) during the main shock show that the rupture had strike-slip as well as thrust faulting components. The post-seismic TEC disturbances propagated over a longer distance from the epicenter (approximately 1,500 km) in the northern direction and shorter distances (approximately $700 \mathrm{~km}$ ) on the southern side. The velocity estimation, using the distance between the IPPs at different times and the corresponding time values, shows that the post-seismic TEC disturbances traveled at the acoustic wave velocity. The wavelet analysis of TEC fluctuations, detrended over a period of $105 \mathrm{~s}$, clearly demonstrate the presence of oscillations lasting for $1 \mathrm{~h}$ with a frequency of 
approximately $4 \mathrm{mHz}$, and this frequency is close to the atmospheric resonance frequencies $(3.7$ and $4.4 \mathrm{mHz})$. The normal modes need to be recalculated to consider the depth of the ocean and other variables near the epicenter of these earthquakes. They would then provide more realistic acoustic resonant frequencies in this case study. The estimated propagation velocities of the postseismic TEC disturbances during the main shock $(0.89 \mathrm{~km} / \mathrm{s})$ and aftershock $(0.77 \mathrm{~km} / \mathrm{s})$ confirm the presence of acoustic frequencies as the generative mode for the observed TEC fluctuations. The present doublet earthquake event provided an opportunity to minimize the ambiguities in identifying even smallscale seismic-induced ionospheric disturbances. The various characteristics of post-seismic ionospheric disturbances, such as generative frequency, propagation velocity, and propagation direction, are addressed, and their respective physical mechanisms are discussed.

\section{Abbreviations}

CID: Co-seismic ionospheric disturbances; dTEC: Detrended TEC; GPS: Global positioning system; IAGA: International Association of Geomagnetism and Aeronomy; IGRF: International Geomagnetic Reference Field;

IGS: International GNSS Service; IPPS: Ionospheric piercing points; PRN: Pseudo random number; RINEX: Receiver-independent exchange; STID: Seismo-traveling ionospheric disturbance; SuGAr: Sumatran GPS Array; TEC: Total electron content.

\section{Competing interests}

The authors declare that they have no competing interests.

\section{Authors' contributions}

AS carried out the analysis and drafted the initial text. MB evaluated the initial text for scientific content and co-drafted the manuscript. CDR and DSR gave very important suggestions at various stages of this work. DSR co-drafted the manuscript. MK contributed to the fault mechanism analysis. All authors read and approved the final manuscript.

\section{Acknowledgements}

The authors gratefully acknowledge the Scripps Orbit and Permanent Array Center (SOPAC) for providing GPS data from the IGS and SuGAr networks. AS is grateful to the Department of Science and Technology (DST), India, for providing the research fellowship. This work is part of the new interdisciplinary initiative of the Indian Institute of Geomagnetism (IIG), Navi Mumbai, India. This work is supported by the Department of Science and Technology (DST), India.

Received: 13 August 2014 Accepted: 28 January 2015

Published online: 05 March 2015

\section{References}

Astafyeva E, Heki K (2009) Dependence of waveform of near-field coseismic ionospheric disturbances on focal mechanisms. Earth Planets Space 61:939-943

Astafyeva E, Heki K, Kiryushkin V, Afraimovich EL, Shalimov S (2009) Two-mode long-distance propagation of coseismic ionosphere disturbances. J Geophys Res 114:A10307, doi:10.1029/2008JA013853

Astafyeva E, Shalimov S, Olshanskaya E, Lognonné P (2013) lonospheric response to earthquakes of different magnitudes: larger quakes perturb the ionosphere stronger and longer. Geophys Res Lett 40:1675-1681, doi:10.1002/grl.50398

Astafyeva E, Rolland LM, Sladen A (2014) Strike-slip earthquakes can also be detected in the ionosphere. Earth Planet Sci Lett 405:180-193

Calais E, Minster JB (1998) GPS, earthquakes, the ionosphere, and the Space Shuttle. Phys Earth Planet Inter 105:167-181, doi:10.1016/S0031-9201(97) 00089-7
Choosakul N, Saito A, lyemori T, Hashizume M (2009) Excitation of 4-min periodic ionospheric variations following the great Sumatra-Andaman earthquake in 2004. J Geophys Res 114:A10313, doi:10.1029/2008JA013915

Heki K, Ping J (2005) Directivity and apparent velocity of the coseismic ionospheric disturbances observed with a dense GPS array. Earth Planet Sci Lett 236:845-855, doi:10.1016/j.epsl.2005.06.010

Kakinami Y, Kamogawa M, Tanioka Y, Watanabe S, Gusman AR, Liu JY, Watanabe Y, Mogi T (2012) Tsunamigenic ionospheric hole. Geophys Res Lett 39:L00G27, doi:10.1029/2011GL050159

Kakinami Y, Kamogawa M, Kakinami Y, Watanabe S, Odaka M, Mogi T, Liu J-Y, Sun Y-Y, Yamada T (2013) lonospheric ripples excited by superimposed wavefronts associated with Rayleigh waves in the thermosphere. J Geophys Res Space Physics 118:905-911, doi:10.1002/jgra.50099

Liu J-Y, TsaiYB MKF, Chen Yl, Tsai HF, Lin CH, Kamogawa M, Lee CP (2006) lonospheric GPS total electron content (TEC) disturbances triggered by the 26 December 2004 Indian Ocean tsunami. J Geophys Res 111:A05303, doi:10.1029/2005JA011200

Liu J-Y, Tsai HF, Lin CH, Kamogawa M, Chen Yl, Lin CH, Huang BS, Yu SB, Yeh YH (2010) Coseismic ionospheric disturbances triggered by the Chi-Chi earthquake. J Geophys Res 115:A08303, doi:10.1029/2009JA014943

Liu J-Y, Chen CH, Lin CH, Tsai HF, Chen CH, Kamogawa M (2011) lonospheric disturbances triggered by the 11 March 2011 M9.0 Tohoku Earthquake. J Geophys Res 116:A06319, doi:10.1029/2011JA016761

Lognonné P, Clévédé E, Kanamori H (1998) Computation of seismograms and atmospheric oscillations by normal-mode summation for a spherical Earth model with realistic atmosphere. Geophys J Int 135:388-406

Mannucci AJ, Wilson BD, Edwards CD (1993) A new method for monitoring the Earth's ionospheric total electron content using the GPS Global Network. The Institute of Navigation, Alexandria, VA, pp 1323-1332, Proceedings of ION GPS-93, the 6th International Technical Meeting of the Satellite Division of The Institute of Navigation, Salt Lake City, UT, 22-24 September

Matsumura M, Saito A, lyemori T, Shinagawa H, Tsugawa T, Otsuka Y, Nishioka M, Chen $\mathrm{CH}$ (2011) Numerical simulations of atmospheric waves excited by the 2011 off the Pacific coast of Tohoku Earthquake. Earth Planets Space 63(7):885-889

Meng L, Ampuero J-P, Stock J, Duputel Z, Luo Y, Tsai VC (2012) Earthquake in a maze: compressional rupture branching during the $2012 \mathrm{M}_{\mathrm{w}} 8.6$ Sumatra Earthquake. Science 337:724-726, doi:10.1126/science.1224030

Okada Y (1985) Surface deformation due to shear and tensile faults in a half-space. Bull Seismol Soc Am 75:1135-1154

Oliver JA (1962) A summary of observed seismic surface wave dispersion. Bull Seismol Soc Am 52:81-86

Otsuka Y, Kotake N, Tsugawa T, Shiokawa K, Ogawa T, Effendy SS, Kawamura M, Maruyama T, Hemmakorn N, Komolmis T (2006) GPS detection of total electron content variations over Indonesia and Thailand following the 26 December 2004 earthquake. Earth Planets Space 58:159-165

Perevalova NP, Sankov VA, AstafyevaE ZAS (2014) Threshold magnitude for ionospheric TEC response to earthquakes. JAtmos Solar-TerrPhys 108:77-90

Pollitz F, Sevilgen V, Stein RS, Bürgmann R (2012) The 11 April 2012 east Indian Ocean earthquake triggered large aftershocks worldwide. Nature 490:250-253, doi:10.1038/nature11504

Rolland L, Lognonné P, Astafyeva E, Kherani A, Kobayashi N, Mann M, Munekane $H$ (2011a) The resonant response of the ionosphere imaged after the 2011 Tohoku-Oki earthquake. Earth Planet Space 63:853-857, doi:10.5047/ eps.2011.06.020

Rolland LM, Lognonné P, Munekane H (2011b) Detection and modeling of Rayleigh wave induced patterns in the ionosphere. J Geophys Res 116:A05320, doi:10.1029/2010JA016060

Saito A, Tsugawa T, Otsuka Y, Nishioka M, lyemori T, Matsumura M, Saito S, Chen CH, Goi Y, Choosakul N (2011) Acoustic resonance and plasma depletion detected by GPS total electron content observation after the 2011 off the Pacific coast of Tohoku Earthquake. Earth Planets Space 63(7):863-867

Tanaka T, Ichinose T, Shibata T, Okuzawa T, Sato Y, Ogawa T, Nagasawa C (1984) HF-Doppler observations of acoustic waves excited by the Urakawa-Oki earthquake on 21 March 1982. JAtmos Solar-TerrPhys 46:233-245

Tsugawa T, Saito A, Otsuka Y, Nishioka M, Maruyama T, Kato H, Nagatsuma T, Murata KT (2011) lonospheric disturbances detected by GPS total electron content observation after the 2011 off the Pacific coast of Tohoku Earthquake. Earth Planets Space 63:875-879, doi:10.5047/eps.2011.06.035 
Yao YB, Chen P, Wu H, Zhang S, Peng W (2012) Analysis of ionospheric anomalies before the 2011 Mw 9.0 Japan earthquake. Chinese Sci Bull 57(5):500-510, doi:10.1007/s11434-011-4851-y

Yue H, Lay T, Koper KD (2012) En échelon and orthogonal fault ruptures of the 11 April 2012 great intraplate earthquakes. Nature 490:245-249, doi:10.1038/ nature 11492

Submit your manuscript to a SpringerOpen ${ }^{\mathcal{D}}$ journal and benefit from:

- Convenient online submission

- Rigorous peer review

- Immediate publication on acceptance

- Open access: articles freely available online

- High visibility within the field

- Retaining the copyright to your article

Submit your next manuscript at $\gg$ springeropen.com 